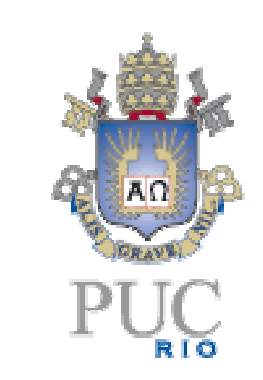

Alexandre dos Santos Silva

\title{
A intervenção humanitária em três quase-Estados africanos: Somália, Ruanda e Libéria
}

\section{Dissertação de Mestrado}

Dissertação apresentada como requisito parcial para obtenção do título de Mestre pelo Programa de Pós-Graduação em Relações Internacionais da PUC-Rio.

Orientador: João Franklin Abelardo Pontes Nogueira 


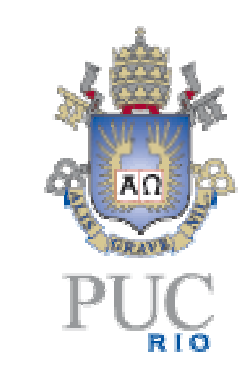

Alexandre dos Santos Silva

\title{
A intervenção humanitária em três quase-Estados africanos: Somália, Ruanda e Libéria
}

Dissertação apresentada como requisito parcial para obtenção do título de Mestre pelo Programa de PósGraduação em Relações Internacionais da PUC-Rio. Aprovada pela Comissão Examinadora abaixo assinada.

\author{
João Franklin Abelardo Pontes Nogueira \\ Orientador \\ Instituto de Relações Internacionais - PUC-Rio
}

Mônica Herz

Instituto de Relações Internacionais - PUC-Rio

Nizar Messari

Instituto de Relações Internacionais - PUC-Rio

João Franklin Abelardo Pontes Nogueira

Coordenador(a) Setorial do Centro de Ciências Sociais - PUC-Rio

Rio de Janeiro, 15 de setembro de 2003 
Todos os direitos reservados. É proibida a reprodução total ou parcial do trabalho sem autorização da universidade, do autor e do orientador.

\section{Alexandre dos Santos Silva}

Graduou-se em Jornalismo na Universidade do Estado do Rio de Janeiro (Uerj) em 1996. Trabalhou no jornal O Fluminense, na Associação Brasileira de Imprensa (ABI) e na TV Globo, no canal de notícias Globo News, onde foi repórter, editor e produtor. A partir de 2003 foi produtor e editor do programa Sem Fronteiras, na Globo News, que debate questões de política e relações internacionais.

Ficha Catalográfica

Silva, Alexandre dos Santos

Analise das intervenções humanitárias ocorridas na Somália, em Ruanda e na Libéria a partir do entendimento que cada um desses países se caracteriza como um quase-Estado e que essa condição foi uma das principais responsáveis pelo colapso das instituições estatais em cada um deles.

214 f.:il. ; 29,7 cm

Dissertação (mestrado) - Pontifícia Universidade Católica do Rio de Janeiro, Instituto de Relações Internacionais.

Incluí referências bibliográficas.

Intervenção humanitária; intervenção; ONU; Conselho de Segurança; segurança; quase-Estados; Ruanda; Libéria; Somália; Ecowas; Ecomog; Comunidade Econômica dos Países da África Ocidental; Unosom I; Unosom II; Unomil; Unomir. 
À memória de meu pai e amigo, Elenus de Abreu e Silva, falecido em maio de 2002. Nada nos aborrece!

Aos meus irmãos, João, Marcos, Mário e Rafael, e a toda minha família; por passarem o último ano convivendo indiretamente com os problemas da Somália, de Ruanda e da Libéria. 


\section{Agradecimentos}

- Ao meu orientador, João Pontes Nogueira, pela compreensão nos momentos difíceis e por ter sempre afiado a minha perseverança;

- À Ângela Lindenberg, Denise Nascimento e Maristela Pereira, por terem compreendido a importância da minha condição de discente e por terem ajudado nos momentos em que meu rendimento na área acadêmica interferiu diretamente no meu rendimento na área profissional. À Fernanda Esteves, que sempre incentivou o comportamento "intelectualmente inquieto";

- Às "mosqueteiras" Eduarda, Joyce e Liana; e à Luciana (do Núcleo de Documentação do IRI), pelos momentos de incentivo e pelas constantes injeções de esperança;

- A José Carlos Monteiro (Oh, Captain, my Captain!), Francisco Carlos Teixeira e Márcio Scalercio pelas opiniões e pela preocupação que tiveram com minha pesquisa e com o desenvolvimento deste trabalho;

- À Maria Helena, do Instituto de Relações Internacionais da PUC-Rio, apelidada carinhosamente de M.H. (e minha "santa desatadora dos nós"), pelas infindáveis lembranças das datas de matrícula, dos prazos de entrega de inúmeros trabalhos e pela extrema paciência em me chamar a atenção para todos os trâmites burocráticos pelos quais tive que passar na condição de mestrando. À Regina e Jaqueline, também da secretaria do IRI, pela paciência e pela ajuda;

- Aos funcionários da Biblioteca da PUC, em especial a Alexandre, André, Edinho, Francisco, Luciano, Sandra e Sebastião pela solicitude e pelas constantes lembranças das datas de renovação dos livros;

- À Fátima e Dinah, que estiveram comigo no início do caminho; à Deborah, que me acompanhou em parte do trajeto; à Cristina, que tanto me apoiou e ajudou e 
à Eva, que seguiu comigo até a chegada.

- À 'Demônios do Dez”, meus amigos de Jaleco e de Rio 40, pelo apoio etílico e espiritual.

- À minha avó Amélia e à dona Dilene (mãe da Liana) pelas orações.

- À Ana Sommer Benjamin (Ani), por ter estado no lugar certo e na hora certa. Por tudo e muito mais. 


\section{Resumo}

Silva, Alexandre dos Santos. A intervenção humanitária em três quaseEstados africanos: Somália, Ruanda e Libéria. Rio de Janeiro, 2003. 214p. Dissertação de Mestrado - Instituto de Relações Internacionais, Pontifícia Universidade Católica do Rio de Janeiro.

O objetivo deste trabalho é analisar as intervenções humanitárias ocorridas na Somália, em Ruanda e na Libéria a partir do entendimento que cada um desses países se caracteriza como um quase-Estado e que essa condição foi uma das principais responsáveis pelo colapso das instituições estatais em cada um deles.

Este trabalho inicia apresentando e discutindo os conceitos de 'intervenção humanitária", "quase-Estado" e "colapso do Estado" e segue numa análise dos antecedentes históricos que levaram cada país ao colapso e às respectivas intervenções internacionais (ONU na Somália; França em Ruanda; e Ecowas na Libéria). Por fim, descreve os equívocos cometidos em cada uma das três intervenções e suas conseqüências para a resolução ou prolongamento dos conflitos.

\section{Palavras-chave}

Intervenção humanitária; intervenção; ONU; Conselho de Segurança; segurança; quase-Estados; Ruanda; Libéria; Somália; Ecowas; Ecomog; Comunidade Econômica dos Países da África Ocidental; Unosom I; Unosom II; Unomil; Unomir. 


\section{Abstract}

Silva, Alexandre dos Santos; Nogueira, João Franklin Abelardo Pontes. The humanitarian intervention in three african quasi-States: Somalia, Rwanda and Liberia. Rio de Janeiro, 2003, 214p. MSc. DissertationInstituto de Relações Internacionais, Pontifícia Universidade Católica do Rio de Janeiro.

The aim of this work is to describe the humanitarian interventions in Somalia, Rwanda and Liberia from the understandings of each country as quaseState and this condition as one of the major causes for the collapse of each state's institutions.

This work begins describing and discussing the concepts of "humanitarian intervention", "quasi-State" and "State collapse" and analyses the historic facts that precedes the collapse of each country and the respective interventions (the UN's in Somalia; the French's in Rwanda; and the Ecowas' in Liberia). The final part describes the equivocals done in each one and the consequences for the resolution or the extending of the conflicts.

\section{Keywords}

Humanitarian intervention; intervention; UNO; Security Concil; security; quasi-States; Rwanda; Liberia; Somalia; Ecowas; Ecomog; Economic Cominuty of West African States; Unosom I; Unosom II; Unomil; Unomir. 


\section{Sumário}

1. Introdução 13

1.1 Intervenção e "Intervenção humanitária” 13

$\begin{array}{ll}1.2 \text { Legitimidade } & 16\end{array}$

$\begin{array}{ll}1.3 \text { Objetivos deste trabalho } & 20\end{array}$

2. 'Quase-Estados": um conceito para identificar as realidades somali, ruandesa e liberiana no fim do século XX 23

2.1 O quase-Estado jacksoniano 23

2.2 A condição de quase-Estado levando ao colapso estatal 28

2.3 Somália, um quase-Estado 30

2.4 Ruanda, um quase-Estado 35

2.5 Libéria, um quase-Estado $\quad 39$

3. A intervenção humanitária na Somália 44

3.1 Introdução 45

3.2 Antecedentes imediatos 46

3.3 A ação da Unitaf e as reuniões pela paz 56

3.4 A ação da Unosom II e a recompensa pela cabeça de Aideed 63

4. A intervenção humanitária em Ruanda 69

4.1 Introdução $\quad 69$

4.2 Antecedentes imediatos $\quad 71$

4.3 As discussões em Arusha e os novos embates no norte 76

4.4 O genocídio, a não-intervenção da ONU, a passividade

da Unamir e a intervenção francesa $\quad 82$

4.5 A intervenção humanitária (francesa) aprovada pelo

Conselho de Segurança 
5. A intervenção humanitária na Libéria 91

5.1 Introdução 91

5.2 Interlúdio: a criação da Comunidade Econômica dos

Estados da África Ocidental (Ecowas) e o estabelecimento

do Ecomog como instrumento de intervenção ad hoc 92

5.3 Antecedentes imediatos 98

5.4 A atuação do Ecomog e os acordos de paz 102

5.5 Missão cumprida (?): eleições diretas e a vitória de Taylor 119

6. Conclusão

7. Referências bibliográficas 132

$\begin{array}{ll}7.1 \text { Bibliografia virtual } & 139\end{array}$

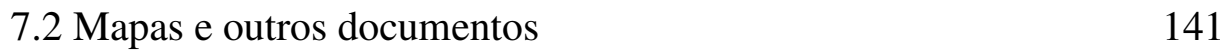

8. Anexos 145

8.1 Somália: linha do tempo 145

8.2 Ruanda: linha do tempo 150

8.3 Libéria: linha do tempo 156

8.4 Algumas Resoluções do Conselho de Segurança referentes à Somália 164

8.5 Algumas Resoluções do Conselho de Segurança referentes a Ruanda

8.6 Algumas Resoluções do Conselho de Segurança referentes à Libéria 


\section{Lista de Figuras}

Figura 1- Mapa político da Somália 44

Figura 2 - Principais clãs e subclãs somalis

Figura 3 - Mapa da República da Somalilândia

Figura 4 - Mapa de Ruanda com as principais cidades

69

Figura 5 - Países integrantes da Ecowas

93

Figura 6 - Mapa político da Libéria

99 